\title{
EFFECTS OF GEOSPATIAL DATA SOURCES ON THE IDENTIFICATION AND CHARACTERIZATION OF BURNT AREAS IN PORTUGAL
}

\author{
C.C. Fonte ${ }^{1,2,1 *}$ J. Patriarca ${ }^{1,2}$, D. Duarte ${ }^{2}$ \\ ${ }^{1}$ University of Coimbra, Department of Mathematics, Largo D. Dinis, Coimbra, Portugal - cfonte@mat.uc.pt \\ ${ }^{2}$ Institute for Systems Engineering and Computers at Coimbra - INESC Coimbra, Rua Sílvio Lima, Pólo II, Coimbra, Portugal
}

Commission IV, WG IV/III

KEY WORDS: Burnt areas, Land Use Land Cover, Corine Land Cover, COS, Uncertainty.

\begin{abstract}
:
The work presented in this paper compares the burnt areas in continental Portugal in 2017 and 2018 mapped by three initiatives, namely the Portuguese Institute of Nature and Forests Conservation (ICNF), the Corine Land Cover (CLC) inventory of the Copernicus programme and the European Forest Fire Information System (EFFIS). Then, the Land Use Land Cover (LULC) classes affected by the 2017 burnt areas mapped by ICNF are analysed considering CLC 2018 and the 2018 LULC map produced by the Portuguese National Mapping Agency (Direção Geral do Território) - "Carta de Ocupação do Solo" (COS 2018). To enable a comparison between the classes of both LULC products, a nomenclature was selected and both CLC 2018 and COS 2018 were mapped into the chosen classes. The comparison of the burnt area's extent showed that there are large differences in both area and levels of detail between the analysed data sources. The results regarding the LULC classes affected by the 2017 fires mapped by ICNF show large differences in terms of burnt area in each class as well as the proportion of the burnt areas associated to the classes. This analysis shows that very different results may be reached if different products are used, and therefore a large level of uncertainty is associated with the conclusions achieved with these products.
\end{abstract}

\section{INTRODUCTION}

Fire is considered to be one of the main factors regarding forest change globally (van der Werf et al., 2006), and one of the main drivers of desertification (Vieira et al., 2015). The identification and characterization of burnt areas within a given time interval and location is central for several tasks, such as the accounting of greenhouse emissions (Prosperi et al., 2020), local, regional and international reporting frameworks which may guide future policy (Bowman et al., 2017) and its impact on, for example, soil quality (Kutiel and Inbar, 1993). Hence, both national and international institutions aim at identifying the burnt areas of a given region to be then used as input in these tasks.

Portugal, a Mediterranean country, with a forest coverage close to $38 \%$ (as in Corine Land Cover 2018 - CLC 2018), is greatly affected by seasonal forest fires where, for example, between January and October 2020 a total of 9394 fires were recorded and 65,887 ha burnt (ICNF, 2020). In Portugal, burnt area assessment is often performed with in-situ analysis (Decree-Law 124/2006, 28th June), which may then be completed recurring to remote sensing techniques using satellite imagery (ICNF, 2020). Parallel to the Portuguese efforts to report on the burnt area of a given year, the Copernicus programme also includes the burnt areas as one of the classes in the Corine Land Cover product. Moreover, the European Forest Fire Information System (EFFIS), which is a modular system consisting of web-based modules, data processing and spatial databases that process and store forest fire information regarding most of the European countries (SanMiguel-Ayanz et al., 2012), also maps burnt areas globally generating a burnt area map every 10 days for the whole globe. Remote sensing and geographic information systems are used by EFFIS to forecast fire danger, early detection of forest fires and damage assessment related to these same fires. However, the mapping of such areas, namely using remote sensing techniques, is still a research topic where several researchers have proposed different mapping methodologies (Grégoire et al., 2003; Simon, 2004; Verhegghen et al., 2016).

Several burnt area products are available for Portugal, from national or international agencies. Given that such products are often used as input for policy making, climate change models and forest fire mitigation; it is critical to understand how the use of a given burnt area product may affect the outcome of any decision making considering such data. This is especially relevant given that not only the total burnt areas might differ but also because the burnt area spatial extent of each of the datasets may be different. Consequently, the land cover affected by a given fire may differ from dataset to dataset, affecting, for example, the estimation of the burnt biomass.

The aim of this paper is to assess the extent to which the use of different data sources regarding burnt areas and Land Use Land Cover (LULC) data may influence the analysis performed for the characterization of the burnt areas. Specifically, the yearly burnt maps for Portugal, produced by the Portuguese Institute of Nature and Forests Conservation (Instituto de Conservação da Natureza e das Florestas- ICNF) are compared with other sources of burnt areas for the years 2017 and 2018, such as the EFFIS and the "Burnt Areas" class of Corine Land Cover (CLC). Moreover, it is assessed how the consideration of each of these maps influence the quantification of burnt area per LULC class for Portugal, and how the characterization of the burnt areas changes when considering two LULC maps, namely, the CLC 2018 and the Portuguese LULC map. The results show that the areas of the burnt areas are very different when comparing CLC 2018 data

$1 *$ Corresponding author 
and the ICNF data, but also the characterization of the burnt areas identified by ICNF is very different when using both LULC products.

\section{DATA}

Two types of data were used for this analysis: 1) the LULC data to characterize the burnt areas and 2) the mapping of burnt areas in continental Portugal.

The LULC information was extracted from the CLC 2018 and the 2018 Portuguese "Carta de Ocupação do Solo" (COS 2018).

The CLC is a pan-European land cover product produced by the Land Monitoring Services of Copernicus European Earth observation programme (Buettner, 2014). CLC is available for the years 1990, 2000, 2006, 2012 and 2018 and the 2018 version has 44 LULC classes at the most detailed level (level 3). Table 1 shows the level 1 and level 2 classes of the nomenclature of CLC 2018. The Minimum Mapping Unit (MMU) of CLC is 25 ha for polygons and the minimum width for linear features is $100 \mathrm{~m}$. The product has a positional accuracy of $100 \mathrm{~m}$ and the overall thematic accuracy is greater than $85 \%$.

\begin{tabular}{|l|l|}
\hline Level 1 & Level 2 \\
\hline 1. Artificial & 1.1 Urban Fabric \\
surfaces & 1.2 Industrial, commercial and transport \\
& units \\
& 1.3 Mine, dump and construction sites \\
& 1.4 Artificial, non-agricultural vegetated \\
areas
\end{tabular}

Table 1. CLC 2018 level 1 and level 2 nomenclature.

COS 2018 is produced by the portuguese national mapping agency (Direção Geral do Território - DGT). The nomenclature of COS 2018 for levels 1 and 2 is shown in Table 2. The MMU of $\operatorname{COS}$ is 1 ha for polygons. The minimum distance between lines and the smallest polygon width is $20 \mathrm{~m}$. The overall thematic accuracy of COS 2018 is still under assessment. However, the accuracy of the previous products was reported to be greater than $85 \%$, and for level 1 , the accuracy was reported to be $97 \%$ for COS 2010 and $96 \%$ for COS 2015 (Caetano et al. 2018).

Three data sets with the burnt areas were analysed, namely:

1. CLC 2018, where the class "Burnt areas" is class 3.3.4 of level 3. CLC 2018 burnt areas consist of burnt natural woody plants and natural herbaceous plants, and bare soil or rock covered with ash.

2. The annual mapping of burnt areas generated by ICNF, as mentioned in section 1, for the years 2017 and 2018.
This is based on field inspections by security forces and municipalities, which is then completed with classified satellite imagery. This is mapped regardless of the LULC present before the fire.

3. The burnt areas mapped by EFFIS for 2017 and 2018 . Burnt areas are extracted from satellite imagery collected with the Advanced Wide Field Sensor. The final resolution of the product is $250 \mathrm{~m}$. This product does not consider both agricultural and urban burnt areas.

\begin{tabular}{|l|l|}
\hline Level 1 & Level 2 \\
\hline 1. Artificial surfaces & 1.1 Urban Fabric \\
& 1.2 Industrial, commercial and \\
& agriculture installations \\
& 1.3 Infrastructures \\
& 1.4 Transports \\
& 1.5 Mine, dump and construction sites \\
& 1.6 Equipment \\
& 1.7 Parks and gardens \\
2. Agriculture & 2.1 Arable land \\
& 2.2 Permanent crops \\
& 2.3 Heterogeneous agricultural areas \\
& 2.4 Protected agricultural and plant \\
& nurseries \\
3. Pastures and semi & 3.1 Forests \\
natural areas & 3.2 Scrub and/or herbaceous \\
& vegetation associations \\
& 3.3 Open spaces with little or no \\
& vegetation \\
4. Agroforestry & 4.1 Agroforestry surfaces \\
surfaces & 5.1 Forests \\
5. Forests & 6.1 Scrubs \\
6. Scrubs & 7.1 Open spaces with little or no \\
7. Open spaces with & vegetation \\
little or no vegetation & 8.1 Wetlands \\
8. Wetlands & 9.1 Inland waters \\
9. Water bodies & 9.2 Aquiculture \\
& 9.3 Transition and costal water areas \\
\hline
\end{tabular}

Table 2. COS 2018 level 1 and level 2 nomenclature.

\section{METHODOLOGY}

The methodology used for this analysis includes two phases. The first phase aims to select the burnt areas that will be analysed and the second phase the identification of the LULC classes in the burnt areas, which may be used to characterize the areas affected by the fires.

\subsection{Choice of the burnt areas for analysis}

To identify which sources of data about burnt areas are comparable, an analysis was made to determine the correspondence between the CLC 2018 data with the other two sources of burnt areas. Figure 1 shows the burnt areas extracted from CLC 2018, from ICNF 2017, ICNF 2018 and EFFIS 2017. The comparison of the burnt areas between CLC 2018 and the data extracted from ICNF confirms that the burnt areas shown in CLC 2018 correspond to the burnt areas in 2017 and not in 2018. This is also supported by the data shown in Table 3, which shows 
the area of the burnt regions in CLC 2018, ICNF 2017 and 2018 data and the intersection between CLC 2018 and the two datasets from ICNF. Most of the burnt areas mapped in CLC 2018 are also included in the ICNF 2017 data and there is almost no overlap of those with the ICNF 2018 burnt areas. Therefore, for the remaining analysis, the burnt areas identified in CLC 2018 and ICNF 2017 were used. Figure 1 also shows the burnt areas available in EFFIS. It is clear that these regions have much less detail than the other two data sets, so no further analysis was made using the EFFIS areas.



Figure 1. Burnt areas in Portugal available in CLC 2018, the mapping of burnt areas for 2017 and 2018 by ICNF and EFFIS 2017.

\begin{tabular}{|l|c|}
\hline Data & Total area (ha) \\
\hline Burnt areas in CLC 2018 & 69,666 \\
Burnt areas in ICNF 2017 & 557,743 \\
Burnt areas in ICNF 2018 & 40,279 \\
Intersection between burnt areas in CLC & 64,854 \\
2018 and ICNF 2017 & \\
Intersection between burnt areas in CLC & 35 \\
2018 and ICNF 2018 & \\
\hline
\end{tabular}

Table 3. Area of the burnt areas according to the different data sources and their intersection.

\subsection{Analysis of the LULC classes in the burnt areas}

To assess the LULC classes that were affected by the burnt areas when using CLC 2018 and COS 2018, and be able to compare the results obtained with both data sets, it was necessary to define a nomenclature that could be mapped to classes of both products. Table 4 shows the selected classes and their mapping into the CLC 2018 and COS 2018 classes. The mapping with CLC 2018 considers in some cases level 1 classes and in other cases level 2 classes, while the mapping with COS 2018 considers only level 1 classes.

\begin{tabular}{|l|l|c|c|}
\hline Code & Classes & $\begin{array}{c}\text { CLC 2018 } \\
\text { class code }\end{array}$ & $\begin{array}{c}\text { COS 2018 } \\
\text { class code }\end{array}$ \\
\hline 1 & Artificial Surfaces & 1 & 1 \\
2 & Agricultural areas & $2.1 / 2.2 / 2.4$ & $2 / 4$ \\
3 & Pastures & 2.3 & 3 \\
4 & Forest & 3.1 & 5 \\
5 & Scrub & 3.2 & 6 \\
6 & Open Spaces with little & 3.3 & 7 \\
7 & or no vegetation & 4 & 8 \\
8 & Wetlands & 5 & 9 \\
\hline
\end{tabular}

Table 4. Considered classes and their mapping to the CLC 2018 and COS 2018 nomenclatures.

To identify the LULC classes that were affected by the fires, the following analyses were made:

1. The intersection of the LULC maps obtained with the CLC 2018 and COS 2018 with the ICNF 2017 burnt areas was made.

2. The regions identified in CLC 2018 as burnt do not have a pre-fire LULC class available. Therefore, to assess how these areas might influence the comparison of the areas affected by fires in each class considering both LULC data sources, the pre-fire class of the burnt areas in CLC 2018 was estimated with COS 2018 data, by intersecting this map with the CLC 2018 burnt areas.

\section{RESULTS}

Figure 2 and Figure 3 show the LULC maps resulting from the conversion of, respectively, COS 2018 and CLC 2018 into the considered classes, shown in Table 4.

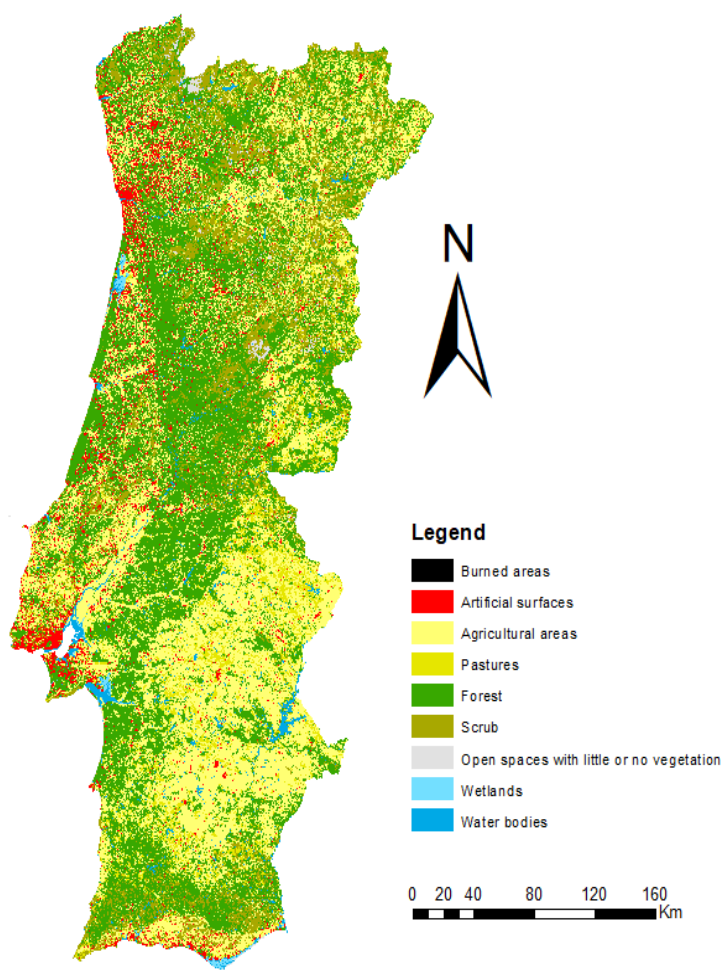

Figure 2. LULC map obtained from COS 2018. 




Figure 3. LULC map obtained from CLC 2018.
Table 5 shows the areas, in ha per class, of the LULC classes existing in the burnt areas mapped in the ICNF 2017 dataset, as well as the difference between the area obtained per class from each product, both in ha and percentage relative to the area obtained with CLC 2018 data. The results show that the differences of area obtained from both products is very large for some classes. The largest absolute difference obtained was for the class Forest, with a difference between the two datasets of 202,827 ha, which corresponds to an increase of $130 \%$ from CLC 2018 to COS 2018. The class with the second largest difference is the class Scrub, with an absolute value of 121,672 ha, which corresponds to a decrease of 50\% from CLC 2018 to COS 2018. Two other classes show smaller absolute differences, as these classes occupy smaller regions, but even larger differences in percentage. The class Pastures shows a difference of $318 \%$ when comparing the data obtained from CLC 2018 and COS 2018, while the class Artificial Surfaces shows a difference of $148 \%$, corresponding to an increase of 5,081 ha between the artificial areas mapped when using CLC 2018 and COS 2018. This shows that the difference between the areas mapped when using these datasets is larger than the whole artificial area mapped by CLC 2018 in the region under analysis.

\begin{tabular}{|l|l|c|c|c|c|}
\hline \multirow{2}{*}{ Code } & Classes & Area in ICNF 2017 burnt areas (ha) & \multicolumn{2}{|c|}{ Difference } \\
\cline { 3 - 6 } & & CLC 2018 & COS 2018 & ha & \% relative to CLC 2018 \\
\hline 0 & Burnt areas & 64,854 & 0 & $-64,854$ & -100 \\
1 & Artificial Surfaces & 3,442 & 8,523 & 5,081 & 148 \\
2 & Agricultural areas & 84,272 & 56,888 & $-27,384$ & -32 \\
3 & Pastures & 1,453 & 6,070 & 4,617 & 318 \\
4 & Forest & 156,383 & 359,210 & 202,827 & 130 \\
5 & Scrub & 242,004 & 120,332 & $-121,672$ & -50 \\
6 & Open Spaces with little or no vegetation & 4,058 & 5,072 & 1,014 & 25 \\
7 & Wetlands & 81 & 94 & 13 & 16 \\
8 & Water bodies & 1,194 & 1,552 & 358 & 30 \\
\hline Sum & & 557,741 & 557,741 & & \\
\hline
\end{tabular}

Table 5. Considered classes and their mapping to the CLC 2018 and COS 2018 nomenclatures.

Figure 4 shows the percentage of the LULC classes included in the 2017 burnt areas mapped by ICNF, considering the classes extracted from CLC 2018 and from COS 2018. As in CLC 2018 for the areas classified as burnt there is no information about the existing class prior to the fire, to determine to what extent that may influence the percentage comparison shown in Figure 4, the COS 2018 LULC classes were assigned to the CLC 2018 burnt areas. The percentage of classes affected by the fires was then computed and are shown in Figure 4 with in middle (striped) columns. The results show that when using COS 2018 the burnt area mapped by ICNF in 2017 was mainly occupied by Forest $(64.4 \%)$, while the second most affect LULC class was Scrub (21.6\%). However, when CLC 2018 is used as the source of LULC classes, these proportions change drastically. Most of the burnt area was Scrub (43.4\% if the burnt areas mapped by CLC 2018 are not considered and $45.9 \%$ if the COS 2018 classes are considered to occupy the burnt areas prior to the fires), and the second most affect class was Forest, with a percentage of only $28.0 \%$ if the burnt areas are not considered and $36.6 \%$ if the COS 2018 classes in these regions are accounted for.



Figure 4. Percentage of the classes area in the burnt areas identified by ICNF in 2017 when considering the LULC data from 1) CLC 2018, 2) CLC 2018 retrieving the COS 2018 classes for the regions classified in CLC 2018 as burnt areas, and 3) COS 2018. 
Figure 5 and Figure 6 show a detail of the LULC classes inside the 2017 ICNF burnt areas when using, respectively, CLC 2018 and COS 2018. The differences in the LULC products are visible both in terms of level of detail (due to the different MMU of the products), but also in terms of confusion in some regions regarding the classification as Forest or Scrub. Another aspect that can be pointed out is the difference between the urban areas
(Artificial surfaces) affected but the fires when comparing the data extracted from both products. Many artificialized regions can be seen in COS 2018 that are absent from CLC 2018. This may also be due to the smaller size of these regions and the MMU of the products, but this difference has a large impact of the assessment of the artificial regions affected, which occupy an area three times larger in the burnt area when using COS 2018.

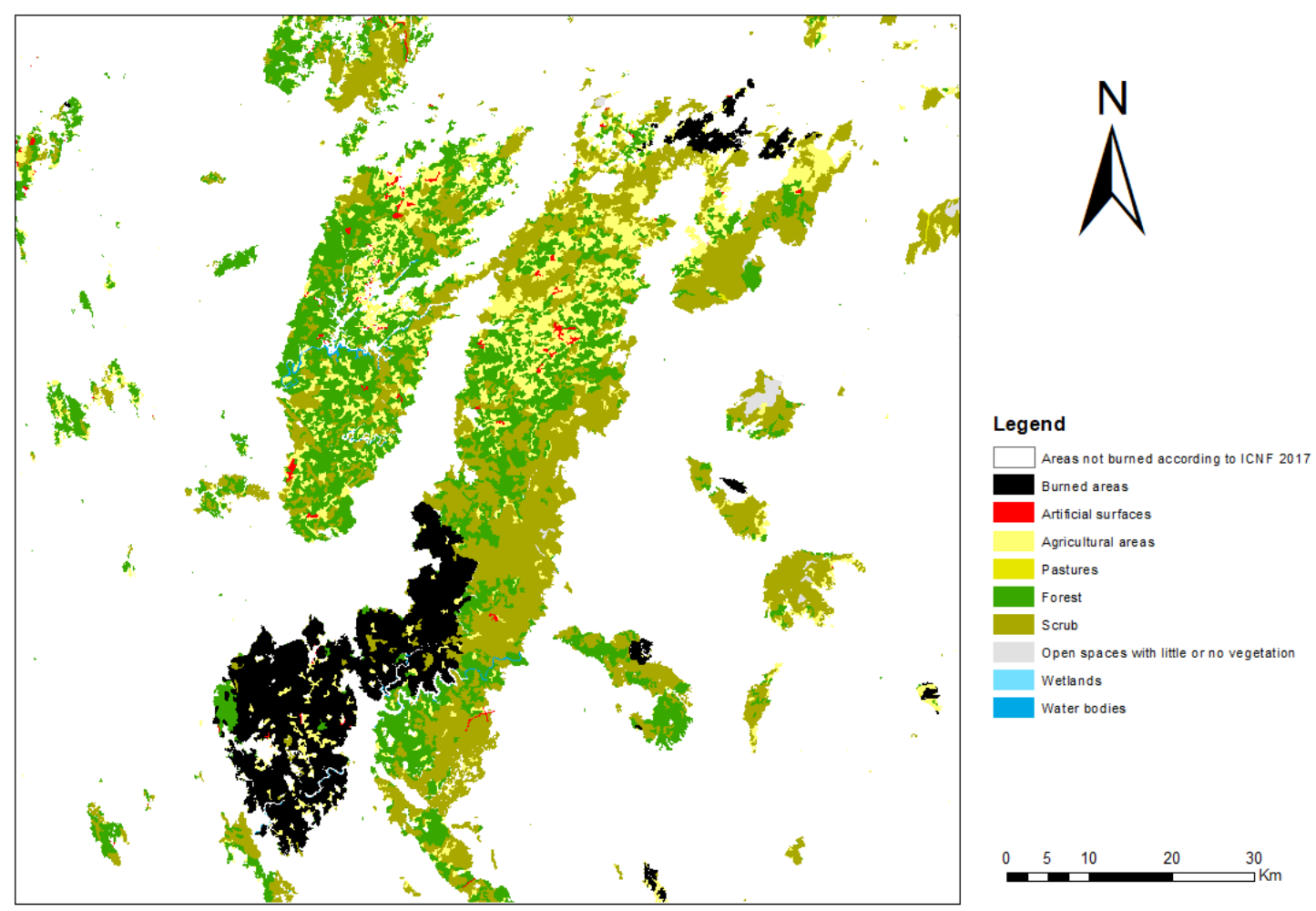

Figure 5. Example of the classes under analysis extracted from CLC 2018 for the ICNF burnt areas of 2017.

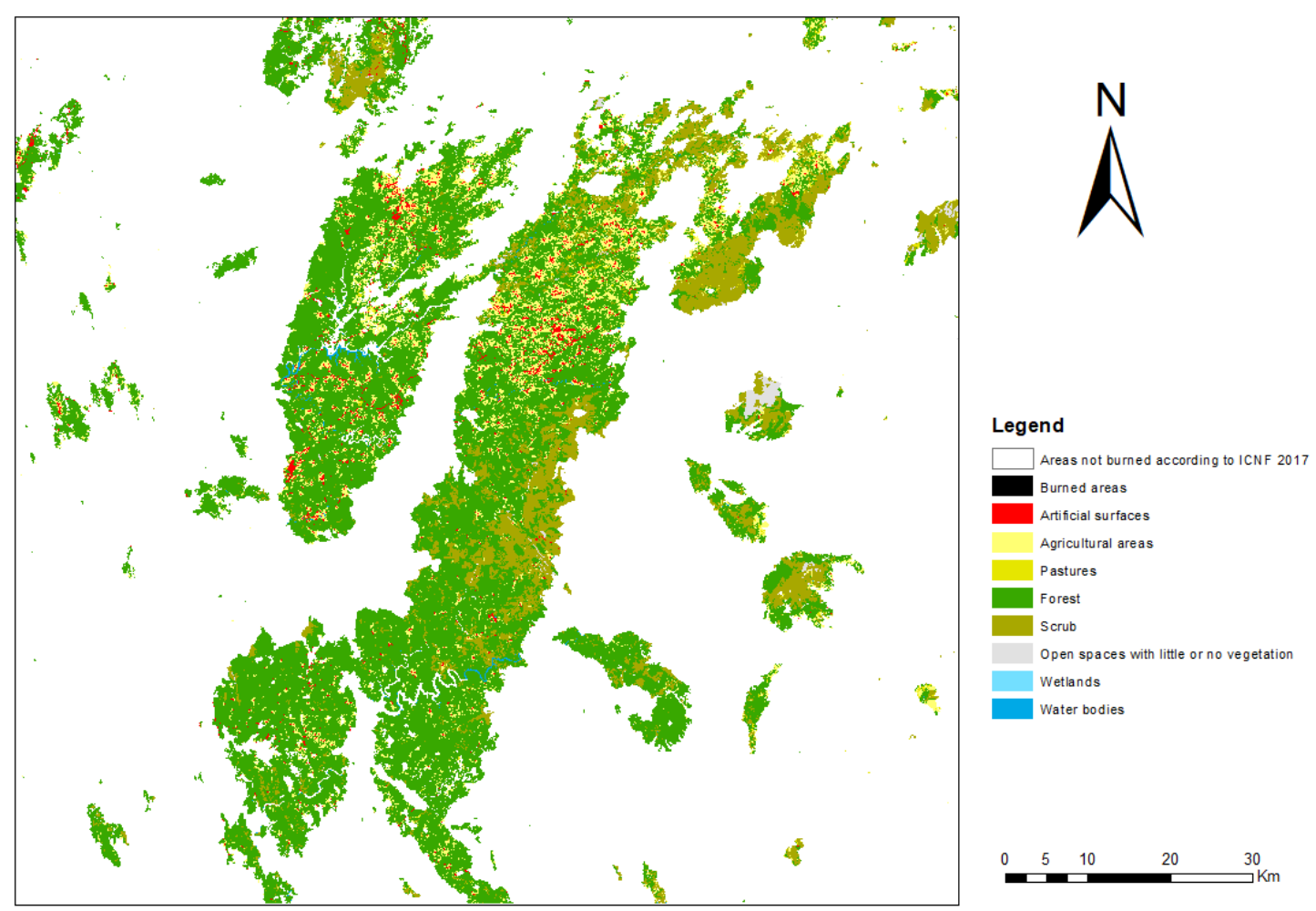

Figure 6. Example of the classes under analysis extracted from COS 2018 for the ICNF burnt areas of 2017. 


\section{CONCLUSIONS}

The analysis presented in this paper shows the divergence between three datasets that report burnt areas for the years 2017 and 2018 in continental Portugal, and the effect that the LULC products used to characterize the burnt areas in 2017 may have over the characterization of these regions. The generation of LULC maps involves the definition of technical specifications, such as the choice of a MMU, but also several sources of uncertainty during production. Therefore, the resulting products may have differences. However, when the use of different products has a large effect over the conclusions obtained from the analysis, this may be a significative problem, as the data about the size, location and characteristics of burnt areas may have impacts over, for example, the assessment of the environmental effects of fires or decision-making regarding mitigation efforts.

The results presented in this paper raise the issue of LULC quality and the uncertainty associated to these products, as well as the impacts they may have over subsequent analyses. This is an important topic related to LULC data, which is usually generated and used as crisp data, where no uncertainty exists. However, in many cases this does not enable a reliable and accurate representation of reality, either due to the considered MMU, classification difficulties or the fact that the real LULC may not have perfect associations with the considered classes. Therefore, this is an area where further developments are necessary so that no drastically different conclusions are reached when using different products that report to have high overall quality.

\section{ACKNOWLEDGEMENTS}

The study has been supported by the Portuguese Foundation for Science and Technology (Fundação para a Ciência e a Tecnologia - FCT) under the project FireLoc grant PCIF/MPG/0128/2017 and grant UIDB/00308/2020.

\section{REFERENCES}

Bowman, D.M.J.S., Williamson, G.J., Abatzoglou, J.T., Kolden, C.A., Cochrane, M.A., Smith, A.M.S., 2017. Human exposure and sensitivity to globally extreme wildfire events. Nat. Ecol. Evol. 1, 0058. https://doi.org/10.1038/s41559-016-0058

Buettner G (2014) CORINE land cover and land cover change products. In: Manakos I, Braun M (eds) Land use and land cover mapping in Europe: practices \& trends. Springer, Dordrecht, pp 55-74

Caetano M, Igreja C, Marcelino F (2018) Especificações Técnicas da Carta de Uso e Ocupação do Solo (COS) de Portugal Continental para 1995, 2007, 2010 e 2015. Direção-Geral do Território

Grégoire, J.-M., Tansey, K., Silva, J.M.N., 2003. The GBA2000 initiative: Developing a global burnt area database from SPOTVEGETATION imagery. Int. J. Remote Sens. 24, 1369-1376. https://doi.org/10.1080/0143116021000044850

\section{ICNF, 2020. 8.o RELATÓRIO PROVISÓRIO DE INCÊNDIOS} RURAIS.

Kutiel, P., Inbar, M., 1993. Fire impacts on soil nutrients and soil erosion in a Mediterranean pine forest plantation. CATENA 20, 129-139. https://doi.org/10.1016/0341-8162(93)90033-L
Prosperi, P., Bloise, M., Tubiello, F.N., Conchedda, G., Rossi, S., Boschetti, L., Salvatore, M., Bernoux, M., 2020. New estimates of greenhouse gas emissions from biomass burning and peat fires using MODIS Collection 6 burned areas. Clim. Change 161, 415-432. https://doi.org/10.1007/s10584-020-02654-0

San-Miguel-Ayanz, J., Schulte, E., Schmuck, G., Camia, A., Strobl, P., Liberta, G., Giovando, C., Boca, R., Sedano, F., Kempeneers, P., McInerney, D., Withmore, C., de Oliveira, S.S., Rodrigues, M., Durrant, T., Corti, P., Oehler, F., Vilar, L., Amatulli, G., 2012. Comprehensive Monitoring of Wildfires in Europe: The European Forest Fire Information System (EFFIS), in: Tiefenbacher, J. (Ed.), Approaches to Managing Disaster Assessing Hazards, Emergencies and Disaster Impacts. InTech. https://doi.org/10.5772/28441

Simon, M., 2004. Burnt area detection at global scale using ATSR-2: The GLOBSCAR products and their qualification. J. Geophys. $\quad$ Res. 109, D14S02. https://doi.org/10.1029/2003JD003622

van der Werf, G.R., Randerson, J.T., Giglio, L., Collatz, G.J., Kasibhatla, P.S., Arellano, A.F., 2006. Interannual variability in global biomass burning emissions from 1997 to 2004. Atmospheric Chem. Phys. 6, 3423-3441. https://doi.org/10.5194/acp-6-3423-2006

Verhegghen, A., Eva, H., Ceccherini, G., Achard, F., Gond, V., Gourlet-Fleury, S., Cerutti, P., 2016. The Potential of Sentinel Satellites for Burnt Area Mapping and Monitoring in the Congo Basin Forests. Remote Sens. 8, 986. https://doi.org/10.3390/rs8120986

Vieira, R.M.S.P., Tomasella, J., Alvalá, R.C.S., Sestini, M.F., Affonso, A.G., Rodriguez, D.A., Barbosa, A.A., Cunha, A.P.M.A., Valles, G.F., Crepani, E., de Oliveira, S.B.P., de Souza, M.S.B., Calil, P.M., de Carvalho, M.A., Valeriano, D.M., Campello, F.C.B., Santana, M.O., 2015. Identifying areas susceptible to desertification in the Brazilian northeast. Solid Earth 6, 347-360. https://doi.org/10.5194/se-6-347-2015 